\title{
A review of East Asian reports of aurorae and comets circa AD 775
}

\author{
J. Chapman ${ }^{1}{ }^{\star}$, D.L. Neuhäuser ${ }^{2}$, R. Neuhäuser ${ }^{3}$, M. Csikszentmihalyi ${ }^{1}$ \\ ${ }^{1}$ Department of East Asian Languages and Cultures, UC Berkeley, Berkeley CA, 94720, United States \\ ${ }^{2}$ Schillbachstrasse 42, 07745 Jena, Germany \\ ${ }^{3}$ Astrophysikalisches Institut, Universität Jena, Schillergässchen 2-3, 07745 Jena, Germany
}

Received 2015 March 4, accepted 2015 June 4

Published online 2015 Aug 1

Key words ${ }^{14} \mathrm{C}$ AD 774/775 - historic Chinese observations - aurorae - comets - history of astronomy

\begin{abstract}
Given that a strong ${ }^{14} \mathrm{C}$ variation in $\mathrm{AD} 775$ has recently been suggested to be due to the largest solar flare ever recorded in history, it is relevant to investigate whether celestial events observed around that time may have been aurorae, possibly even very strong aurorae, or otherwise related to the ${ }^{14} \mathrm{C}$ variation (e.g. a suggested comet impact with Earth's atmosphere). We critically review several celestial observations from AD 757 to the end of the 770s, most of which were previously considered to be true, and in some cases, strong aurorae; we discuss in detail the East Asian records and their wording. We conclude that probably none among the events after AD 770 was actually an aurora, including the event in AD 776 Jan, which was misdated for $\mathrm{AD} 774$ or 775; the observed white qi phenomenon that hapened above the moon in the south-east was most probably a halo effect near the full moon - too late in any case to be related to the ${ }^{14} \mathrm{C}$ variation in $\mathrm{AD} 774 / 5$. There is another report of a similar (or identical) white qi phenomenon above the moon, reported just before a comet observation and dated to AD $776 \mathrm{Jan}$; the reported comet observed by the Chinese was misdated to AD 776, but actually sighted in AD 767. Our critical review of East Asian reports of aurorae circa AD 775 shows some very likely true Chinese auroral displays observed and reported for $\mathrm{AD} 762$; there were also several events prior to AD 771 that may have been aurorae but are questionable.
\end{abstract}

(C) 2011 WILEY-VCH Verlag GmbH \& Co. KGaA, Weinheim

\section{Introduction: ${ }^{14} \mathrm{C}$ variation AD 774/5}

A strong variation in ${ }^{14} \mathrm{C}$ data with a 1-2 yr time resolution around AD 775 was detected in two Japanese (Miyake et al. 2012), one German (Usoskin et al. 2013), one American and one Siberian tree (Jull et al. 2014). A sudden increase in ${ }^{14} \mathrm{C}$ could indicate a strong input of highly energetic particles or $\gamma$-rays into the Earth's atmosphere. A supernova has almost been excluded as the cause of the event (Miyake et al. 2012, Hambaryan \& Neuhäuser 2013); both a solar superflare (e.g. Melott \& Thomas 2012, Usoskin et al. 2013) and a Galactic short gamma-ray burst (Hambaryan \& Neuhäuser 2013) have been proposed as alternatives. While such a large solar super-flare has (otherwise) never been recorded in the last 3000 (M12) or even 11,000 yr (Usoskin \& Kovaltsov 2012) in Intcal ${ }^{14} \mathrm{C}$ data (rate possibly being zero), the rate of short gamma-ray bursts is known from observations of other galaxies to be non-zero, but possibly very low. The super-flare hypothesis was also considered unlikely by Cliver et al. (2014) and Neuhäuser \& Hambaryan (2014) by comparison with the strongest flares of the last two centuries. Hence, it is relevant to search for alternative suggestions.

Liu et al. (2014) pointed to an impact of a comet with Earth's atmosphere on AD 773 Jan 17, presumably seen in a ${ }^{14} \mathrm{C}$ peak in corals at that time, which was, however,

\footnotetext{
^ E-mail: jessechapman@berkeley.edu
}

rejected for three reasons: As mentioned in Neuhäuser \& Hambaryan (2014), given the carbon cycle, ${ }^{14} \mathrm{C}$ would first be incorporated by trees, and later by corals, so that the sequence of events suggested by Liu et al. (2014) is not possible. Both Usoskin \& Kovaltsov (2014) and Melott (2014) showed that comets could not have delivered as much ${ }^{14} \mathrm{C}$ as needed for the $\mathrm{AD} 775$ variation. Then, Chapman et al. (2014) clarified that the Chinese comet observed AD 773 Jan 17 was a normal comet with a long tail, which was then also observed in Japan three days later, and thus could not have collided with the Earth on Jan 17.

Usoskin et al. (2013) claimed to have found a distinct cluster of aurorae between $A D 770$ and 776 which suggests a high solar activity level around $A D 775$. They list 14-16 different events as aurorae from AD 765 to 786, including some presumable aurorae observed in China from AD 770 to 775 . More recently, Zhou et al. (2014) claimed to have found worldwide super-aurorae connected with the suggested solar super-flare:

The strongest AD 775 auroras in the past 11400 years were first successfully identified with the historical records ..., the super auroras were generated in Jan AD 775 and lasted about 8h.

This claim is based mainly on one alleged aurora report from China (but see our Sect. 2.7), but also on two doubtful events from Europe, which were both misdated (Neuhäuser \& Neuhäuser 2014, 2015). 
We review all previously suggested aurora reports as observed from East Asia from AD 757 to 779 . Most of the known East Asian aurora records are found in Matsushita (1956), Keimatsu (1973, 1974) 1 Dai \& Chen (1980), Yau et al. (1995), or Xu et al. (2000). In Sect. 2, we discuss the events which obviously were not aurorae, in Sect. 3, list likely true aurorae, and in Sect. 4, we also give those events, which may or may not have been aurorae. In addition, we also review East Asian observations of comets reported for the mid AD 770s, one of them being in connection with an appearance of white $q i$ (Sect. 5). We conclude our findings in the last section.

First, we comment briefly on medieval Chinese astronomy (and astrology) and in particular their knowledge of what we now understand as aurorae.

Any study of aurorae in medieval China is complicated by the fact that there was no discrete concept of aurorae as such in medieval Chinese astronomy. Scholars have variously identified observations of flowing stars (liu xing) or stars that fall (xing yun), various sorts of halos (huan), and $q i$ as aurorae. Flowing stars and stars that fall in almost every case should be identified with meteors or bolides, while huan (rings) are most likely lunar or solar halo displays; flowing stars in some instances may also refer to comets.

The most likely instances of aurorae in Chinese historical records are identified as $q i$, yet not all or even most observations of $q i$ were indeed aurorae. While $q i$ is variously translated as ether( $(s)$ or vapour(s), material objects, including clouds, planets, stars, comets, and meteors, were thought to be constituted of $q i$ in Chinese cosmology. Because $q i$ was thought to emanate from the Earth itself, often in response to developments in the politico-religious sphere of the imperial court, explanations for aberrant astronomical and meteorological phenomena were grounded in politics.

In the first major treatise on astro-omenology, the Tianguan shu (Treatise on the Celestial Office) Director of Astronomy/Senior Archivist Sima Qian (ca. BC 145 to ca. 86) wrote in the late 2 nd century $\mathrm{BC}$ :

Heaven has the sun and moon, and Earth has yin and yang. Heaven has the Five Planets and Earth has the Five Resources. Heaven has its arrayed lodges, and Earth has its regions. The Three Luminaries [i.e. the sun, moon, and stars] are the essence of yin and yang. Qi originates in the Earth, and the sages unify it and put it to order. (Shiji 27.1342 / Sima Qian 1959)

Two centuries later, circa AD 100, Ban Zhao, in her Treatise on Celestial Patterns, explained virtually all aberrant celestial phenomena, including eclipses, halos, strange clouds, and abberations of $q i$ as issuing from ritual or administrative failures on the part of the ruler and his court:

\footnotetext{
${ }^{1}$ From Matsushita (1956) and Keimatsu (1973, 1974), we include only those which were classified by them with (a high) probability 1-3 (out of five); in Keimatsu $(1973,1974)$, this meant certain for 1 , very probable for 2, and probable for 3; events classified by Keimatsu $(1973,1974)$ with lower probability are discussed in this paper only, because they were classified as true aurorae by others, such as Yau et al. (1995) or Xu et al. (2000).
}

Portents originate in the earth and erupt above into the heavens. When the administration fails here, then transformations appear there, just as shadows are signs of their form, and echoes are responses to sounds. This is why the clear-sighted ruler sees them and awakens, putting himself in order and rectifying his affairs. (Hanshu 26.1273 / Ban Gu et al. 1962)

Aurorae were no exception. Two events listed as probable true aurorae in sections 3.1 and 3.2 below, for example, are immediately followed by a description of political events that occurred in the following year. The Jiu Tang shu "Treatise on Celestial Patterns" associates the appearance of red auroral lights in the sky with the chaotic state of the empire:

In the tenth month of the following year, the Tufan took Chang'an, and Emperor Daizong graced Shaanzhou with his presence as he fled from the northern tribes. (Jiu Tang shu 36.1325)

We are to understand aurorae, and aberrant astronomical and meteorological phenomena in general, as portents, the meanings of which become clear through the writing and reading of history.

Standard historical treatises on celestial patterns (tianwen) often refer to political events happening at court which explain the meaning of celestial signs such as aurorae, thus offering an implicit causal explanation of such events in astrological terms. Unlike Ptolemaic astrology, human beings in the Chinese system were not passive subjects of astrological forces, but their ritual, political, and military actions were thought to produce astronomic and meteorological phenomena. For this reason, court astronomers carefully chronicled aberrant and/or transient astronomical and meteorological phenomena, laying the basis for the compilation of the treatises on celestial patterns in successive dynasties.

The gap in time between when the observations were originally recorded and when they were ultimately included in historical treatises creates another problem. Though the Chinese meticulously recorded the time when observations occurred based on a clear lunar calendar and twelve daily two-hour periods or double-hours, printing had not yet developed in the Tang dynasty (AD 618-907) and so few copies of the records could be kept. Mistranscription and material decay inevitably introduced errors into the texts.

Time-keeping for astronomical events was often quite precise, recording the reign year, month, day, and doublehour when a given event occurred. In contrast to the five night-watches, which varied in length at different times of year, the twelve double-hours (for $24 \mathrm{~h}$ per day) were equal in length (120 min each), measured by clepsydra (water clocks). The mid-point of the first double-hour, $z i$, was reckoned as midnight (Wilkinson 2000). The first night-watch started with the end of the evening twilight (dusk), i.e. 36 min after sunset (since AD 25), and the fifth night-watch ended with the start of the morning twilight (dawn), i.e. 36 min before sunrise (Stephenson 1997). For the convenience 
of the reader, we follow the standard practice of converting Chinese dates to the Julian calendar. When neccessary, we also convert the five night-watches to our clock-hours (in local time) for the given location and time (taking into account the 4-day difference between the Julian and Gregorian calendar by the time of the 8th century).

In terms of practical observation of celestial patterns (i.e. tianwen - a term often imprecisely translated as astronomy or astrology), clouds (yun) and qi were included in a single category, yunqi, and recorded in the same section of the astronomical treatises in the two standard histories of the Tang dynasty. There are numerous astronomical reports for the period under discussion, AD 757-779; the lack of certain kinds of astronomical events in the historical record is not due to a mere lack of reports.

Most recently, Stephenson (2015) compiled a list of East Asian (and European) aurorae for the period AD 767 to 779 in the Jiu Tangshu. For this period, he presents seven texts, six of which he lists as possible aurorae, we also address these six texts. The remaining text concerns black vapour (heiqi) (AD 775 Oct 16, similar to an entry for AD 786 Jan 21), which neither we, nor any previous scholars, consider to have been an aurora. Stephenson (2015) also does not classify the black vapour as an aurora, but as dark clouds seen against a bright (halo) background. His translations of the six common texts are laregly consistent with ours. We comment on differences in Sects. 2.7 and 6.

\section{East Asian observations misinterpreted as aurorae from AD 757 to 779}

We will first discuss a few presumable aurora observations between AD 757 and 779, that have been misinterpreted as aurorae. The original Chinese texts are given in Fig. 1. We give our translations, sometimes compared to previous translations.

\subsection{AD 761 Dec 13: the moon covered Mao}

For AD 761 Dec 13, we find in Liu Xu's (AD 887-946) Jiu Tang shu 36.1325 (Old History of the Tang Dynasty) for the Tang capital Chang'an, which corresponds to the modern city of Xi'an, Shaanxi province, China (square brackets by us):

In that year [the second year of the Dayuan reign period, AD 761], on the guiyi day of the 11th month, at the hai double-hour [21-23h] after the first night drum [in] the second fifth-hour [i.e. in the 2 nd fifth of the double-hour] the moon covered Mao [the Pleiades], and then emerged to its north. It was surrounded by a white halo. The stars of $\mathrm{Bi}$ [in Tau] had white qi amongst them which followed the moon north to penetrate Mao.

The hai double-hour (one of 12 double-hours measured by water clocks) can be considered as quite exactly from 21 to $23 \mathrm{~h}$ local time; the first night drum is the border between the first and second of five night-watches for Xi' an, China $\left(34^{\circ} 16^{\prime} \mathrm{N} 108^{\circ} 54^{\prime} \mathrm{E}, 7.26 \mathrm{~h}\right.$ east of Greenwich), on AD 761 Dec 13, the second night-watch ran from about 20:03h to $22: 38 \mathrm{~h}$, and the event is specified to have occurred during the second fifth of the night watch, from about 20:3421:05h. Hence the event took place close to $21 \mathrm{~h}$ local time. Indeed, an occultation of the Pleiades (Mao) by the moon in the SE occurred at that time. Immediately after the occultation, the moon was slightly north relative to the Pleiades, as reported. In addition, the moon was said to be surrounded by a white halo, i.e., a lunar halo circle or part of it (an arc), which is quite possible close to the full moon (which was on Dec 16). Furthermore, white qi is reported among some stars of Taurus, which could well be some other part of the lunar halo display (e.g. an arc of the halo ring), as it is reported to have followed the moon. Because all these objects (moon, Pleiades, and Taurus) were located in the east and south in the first half of the night, and because the reported $q i$ was always close to the (almost full) moon, it cannot have been an aurora. This event is not listed as an aurora in Yau et al. (1995) nor in Xu et al. (2000).

Keimatsu (1973) translated as follows:

... the moon covered the Mao ... the Pi [in Tau] put on a white halo - and a mass of white vapour coming from the north penetrated the Mao

and he then classified this event as a probable aurora. Keimatsu understands the object of the coverb cong as north and renders it as a preposition, hence from the north. We understand cong as a full verb meaning follow here, with the implied object being the moon. Keimatsu's rendering works grammatically, but given that the moon is already said to be surrounded by a white halo, we think it is more likely that the $q i$ is moving with the moon rather than coming from the north.

The event is also listed as as aurora in Silverman (1998, see also online catalogue ${ }^{3}$.

\subsection{AD 763 Nov: purple qi ... met their horses' heads}

For AD 763 Nov, we find in Su E's (fl. AD 886) Duyang zabian (Duyang Miscellany) (1.1) for China:

In the first year of the Guangde reign period of the Daizong Emperor [AD 763], Tibetan forces invaded the Bian Gate Bridge. The Emperor visited Shan County. The royal armies found themselves at a disadvantage, as there was constantly a purple qi like the canopies of chariots that met their horses' heads. Once they returned to Tong Pass, the Emperor sighed and said: How broad and vast are the waters that send me off to the east ...

\footnotetext{
2 The night was devided into five night-watches of equal lengths, which had different lengths throughout the year (like sun-dial hours).

3 nssdcftp.gsfc.nasa.gov/miscellaneous/aurora, note that this catalog lists sources of aurora reports instead of aurora events, so that events found in several sources are listed several times.
} 
Chinese Texts Section 2:

\subsection{AD 761 Dec 13}

其年建子月癸巳亥時一鼓二籌後，月掩昂，出其北，兼白暈；畢星有白氣從北來貫昂。 (Jiu Tang shu 36.1325 / Liu 1975)

\subsection{AD 763 Nov}

代宗廣德元年, 吐番犯便橋, 上幸陝, 王師不利, 常有紫氣如車盖迎馬首, 及回潼關, 上嘆曰: 何水洋 洋, 送朕東去・・・・・・

(Duyang zabian 1.1 / Su 2007, Dai and Chen 1980)

\subsection{AD 767 Aug 25}

甲戌酉時, 有白氣竟天。

(Jiu Tang shu 11.287/ Liu 1975)

2.4 AD $767 \mathrm{Jul} / \mathrm{Aug}$

惠恭王三年。秋七月。。。帝御紫震殿宴。見三星隕王庭相擊。其光如火進散。 (Samguk sagi, Silla pon'gi 9.95 / Kim 1977)

2.5 AD 773 Aug 9

庚寅酉時, 有氣三道竟天。

(Jiu Tang shu 36.1327 / Liu 1975)

\subsection{AD 774 Oct 13}

（a）九月庚子，朱泚自幽州入朝，是夜，太白入南斗。 (Jiu Tang shu 36.1328 / Liu 1975)

（b）八月戊午夜，熒惑臨月。其月，朱滔自幽州入朝。 (Jiu Tang shu 36.1327 / Liu 1975)

2.7 AD 776 Jan 11/12

十二月甲子夜，東方月上有白氣十餘道，如匹帛，貫五車、東井、輿鬼、觜、參、畢、桝、軒轅，三更 後方散。

(Jiu Tang shu 36.22 / Liu 2007)

十二月丙子夜，東方月上有白氣十餘道，如匹帛，貫五車、東井、輿鬼、觜、參、畢、柳、軒轅，三更 後方散。

(Jiu Tang shu 36.1328 / Liu 1975)

十二月丙子, 月出東方, 上有白氣十餘道, 如匹練, 貫五車及畢、觜嶰、參、東井、熼鬼、柳、軒轅, 中 夜散去。

(Xin Tang shu 32.836 / Ouyang 1975)

Fig. 1 Here, we show the Chinese texts related to events misinterpreted as aurorae. Translation and discussion are given in the Sect. 2. 
There is no direct indication that the purple $q i$ here was seen in the sky, or even at night or in the north, much less that it was an aurora. On the contrary, the text specifies that the $q i$ was constant and on the same level as the horses. It was most likely fog. This event was misinterpreted as an aurora in Dai \& Chen (1980) and also listed as an aurora in Silverman's online catalog for AD 763 Nov (for Tongguan, China). The event is neither listed in Keimatsu (1973) nor Yau et al. (1995) nor in Xu et al. (2000).

\subsection{AD 767 Aug 25: white qi permeating the sky}

For AD 767 Aug 25, we find in Jiu Tang shu 11.287 for Shaanxi, China:

[In the 7th month of the 2nd year of the Dali reign period,] on the jiaxu day [AD 767 Aug 25] during the you hour [17-19h], there was white qi permeating the sky.

Keimatsu (1973) translated as ... white vapour spreading over the sky and then classified it as probable to doubtful. At the capital city of Xi' an in Shaanxi, China, sunset on AD 767 Aug 25 (on the Julian calendar) was at about 18:30h, end of civil twilight at about 18:56h, and the end of astronomical twilight was even at about 19:58h (local times). An aurora observation is extremly unlikely for civil twilight and the first few minutes of nautical twilight. Hence, this is most certainly not an aurora. This event is not listed in Yau et al. (1995) nor in Xu et al. (2000), but is included in Usoskin et al. (2013)

\subsection{AD $767 \mathrm{Jul} /$ Aug: three stars drop down}

For AD 767 (between Jul 30 and Aug 28, most likely Aug 25), we find in the Silla pon'gi (Annals of the Kingdom of Silla, trad. 58 BC-AD 935) section of the Samguk sagi (Historical Records of the Three Dynasties) (9.95), compiled by Kim Pusik (AD 1075-1151) and others during the reign of Injong (AD 1122-1146), the following event in Korea:

In the autumnal seventh month of the third year of King Hyegong (r. 765-780) ... while the King was attending a banquet in the Hall of State Ceremonies, there appeared three stars which fell and collided against one another above the Royal Court. Their light was like fire as it advanced and dispersed.

This is probably listed as an aurora in Usoskin et al. (2013), see footnote no. 4, though it is classified as doubtful in Keimatsu (1973), who translated ... three stars drop down .... The three stars which fell were almost certainly meteors, most likely the Perseids. This event is not listed in Yau et al. (1995) nor in Xu et al. (2000).

\footnotetext{
${ }^{4}$ Usoskin et al. (2013) wrote after citing Keimatsu (1973) and Yau et al. (1995): The next nearest observations are at $A D 767$ and 786 ., so that they included one or more Chinese events in AD 767, probably all three; we discuss all three such events here, Sect. 2.3, 2.4, and 4.3.
}

\subsection{AD 773 Aug 9: 17-19h ... bands of qi}

For AD 773 Aug 9, we find in Jiu Tang shu 36.1327 (Liu 1975) for Shaanxi, China (full moon on Aug 6/7):

Between 17-19h (you double-hour), there were three bands of qi strung across the sky.

Keimatsu (1973) interpreted this report as a probable to doubtful aurora; Usoskin et al. (2013) also listed this event (credible observations from Shanxi Province, China, in $A D$ 770 (twice), $A D$ 773, and $A D$ 775. The next nearest observations are at $A D 767$ and $A D 786$ ). At the city of Xi' an in Shaanxi:5 China, sunset on AD 773 Aug 9 was at about 18:49h and the end of civil twilight was at about 19:16h (local times). Hence, it was observed before the end of civil twilight, probably even before sunset; therefore, the event was not an aurora. It may have been a solar halo display with three pillars of light as three bands of qi strung across the sky. This report is not listed in the aurora catalog of Yau et al. (1995) nor in Xu et al. (2000).

\subsection{AD 774 Oct 13: Red Drops from the ... northeast}

In the astronomical treatise of Jiu Tang shu 36.1328, an event is listed for AD 774 Oct 13 for China as follows:

[(a)] In the ninth month [of the ninth year of the Dali reign period] on the gengzi day [AD 774 Oct 13], the 36th day of the sexagenary cycle, Red Drops from the lands in the northeast (Youzhou) entered the morning light (chao). That night Venus entered the Nandou asterism [Sgr].

There is an additional instance of Red Drops in 36.1327 in connection with the northeast for $\mathrm{AD} 774$ :

[(b)] In the night of the wuwu day of the eighth month [no wuwu day in the eighth month, AD 774], Mars approached the moon. In that month, Red Drops came from the Youzhou [in the northeast] to enter the court.

As the events are recorded in an astronomical treatise, one might suspect that Red Drops refer to meteors or aurorae. However, Red Drops (AD 742-784) in fact turns out to be the unusual sounding name of a Northeastern frontier general who rebelled soon after visiting the imperial court (or chao), which is referred to by the same term as morning light due to the fact that it is held in the morning. Hence, this was a political event rather than an astronomical phenomenon - but as it was listed in the astronomical treatise in the Jiu Tang shu (probably because the Moon, Mars, Venus, and a constellation are mentioned in association with it). We include it here for completeness and to avoid a misinterpretation in the future.

5 The transliteration by Keimatsu (1973) and Usoskin et al. (2013), namely Shanxi, is misleading, because the old Chinese capital Xi' an is located in the Shaanxi Province next to another province called Shanxi Province. 


\subsection{AD 775 Dec 31 or AD 776 Jan 12: white qi above the moon in the east?}

This event has traditionally been given two different dates, having occurred on a jiazi day, the first day in the sexagenary cycle, according to premodern editions of the Jiu Tang shu and on a bingzi day, the 13th day of the sexagenary cycle, according to the Xin Tang shu.

In premodern editions of the Jiu Tang shu, we can find the following text for Xi' an, China:

On the night of the jiazi day of the twelfth month, above the moon in the east, there were more than ten bands of white qi like a bolt of silk, penetrating Wuche (Aur), Dongjing (Gem), Yugui (Cnc), Zui (Ori), Shen (Ori), Bi (Tau), Liu (Hya), and Xuanyuan (Lyn, Leo, and LMi). Just after the third watch, they vanished. (Jiu Tang shu 36.22/Liu 2007)

The modern standard edition of the Jiu Tang shu, Liu 1975 (36.1328), gives the date as bingzi, so that it accords with Ouyang Xiu's (AD 1007-1072) Xin Tang shu (New History of the Tang Dynasty; 1975), Wang Pu's (AD 922982) Tang hui yao (Essential Records of the Tang Dynasty; 2007), and Ma Duanlin's (ca. AD 1254-ca. 1323) Wenxian tongkao (Comprehensive Investigation of Historical Documents; 1986).

The later Xin Tang shu (32.836/Ouyang 1975) uses a different phraseology:

On the bingzi day of the twelfth month, the moon rose in the east, and above it there were more than ten bands of white qi, like bolts of bleached silk, penetrating Wuche and Bi, Zui, Shen, Dongjing, Yugui, Liu, and Xuanyuan. In the middle of the night it dispersed.

Keimatsu (1973) listed this report as a very probable aurora. While he gave two text variants with two different dates in Chinese script, he dated the event to AD 775 Dec 31 (a jiazi day, i.e. 1st day of the sexagenary cycle) in his English translation based on the premodern text of the Jiu Tang shu. Neither Yau et al. (1995) nor Xu et al. (2000) list it as an aurora. However, since the new moon was on AD 775 Dec 26/27, the 4-day-old moon could not be seen in the east on AD 775 Dec 31. This discrepancy can be solved by using the date given in the modern standard Zhonghua edition, AD 776 Jan 12 (a bingzi day), which is consistent with the lunar phase: The full moon was on AD 776 Jan 10/11, so that the moon was in the east in the first half of the night (moonrise at Xi' an on AD 776 Jan 12 was at around 19:40h local time).

All constellations mentioned rise in the first half of the night from the east and move towards the south with the moon. The reported phenomenon is located only and exactly above the moon and nowhere else - apparently even comoving with the moon and the stars; the moon was located in (and around) Leo on Jan 12. This scenario is not consistent with aurorae (partly because it is too bright close to the moon). The bands of white qi, like bolts of bleached silk may have been a lunar halo effect.

Considering all events listed in the catalogues of Yau et al. (1995), Xu et al. (2000), and Keimatsu $(1973,1974)$ for several centuries (AD 550 - 1006), there is only one case where the moon was mentioned expressis verbis in the context of likely true aurora (AD 1006 Apr 14, Xu et al. 1995): In the north, a scarlet vapour extended across the sky, and a white vapour penetrated the moon, where the first (scarlet) vapour is a reliable aurora in the north, while the white vapour may be a halo effect near full moon (Apr 16).

The Jan 776 event is also misdated in the aurora catalog of Silverman (1998) following Keimatsu (1973).

Zhou et al. (2014) listed this particular event as as aurora for 11 Dec 774 , i.e. 17 January $A D 775$ with a slightly different English translation. Apart from the fact that we do not understand the two dates (both of which err by about one year), the duration and the hours of the sighting are not correct: The nearly full moon on the true date of the sighting (AD 776 Jan 12) was visible at the relevant location from around 19:40h local time. As the record specifies that the ten band of white qi were visible above the moon in the east, it is unlikely that the sighting could have started as early as 17-18h, as claimed by Zhou et al. (2014). The records are somewhat vague regarding the time when the phenomenon could no longer be seen. The Jiu Tang shu does specify that it vanished just after the third watch. For Xi' an, China, on the night of AD 776 Jan 12/13, the third night-watch ran from about 22:53h to 01:25h (local time) ${ }^{6}$ just after the third watch suggests some time just after $1: 25 \mathrm{~h}$; this is not inconsistent with the Xin Tang shu, which states that it dispersed in the middle of the night. Given these somewhat illdefined parameters, the phenomenon was most likely visible for less than $\sim 6 \mathrm{~h}$. The records do not support any greater precision.

The massive late imperial encyclopaedia Gujin tushu jicheng (Collectanea of Ancient and Modern Charts and Books; compiled 1726-8) contains a report which conflates the appearance of white $q i$ above the moon in AD $776 \mathrm{Jan}$ with an appearance of a comet (see Sect. 5.2).

Stephenson's (2015) translation of the Jan 776 entry agrees with our own. He first comments that he has little doubt that an auroral display is described here and classifies it as the only confidently identified ... auroral sighting in his section 5.1. In his section 5.3, he describes it as the single definite record of an auroral display. In his section 6 , he calls it the single reliable East Asian report of the aurora. Cliver (2014) reported: From a re-examination of Keimatsu (1973), F.R. Stephenson (2013, priv. comm.) ... suggests ... that a report of more than 10 bands of white vapour on

\footnotetext{
${ }^{6}$ Given the necessarily speculative discussion in Sect. 5.2 regarding a connection with an event on Jan 11 (an yihai day, the 12th day of the sexagenary cycle), it could be that bingzi here means the portion of the night after midnight and yihai meaning the portion of the night before midnight; hence, the event could conceivably have occurred on the night of AD 776 Jan 11/12; considering the bingzi date, it could be the night of AD 776 Jan $12 / 13$.
} 
AD 776 January 12 may be auroral in nature (Cliver et al. 2014). Serious doubts persist, however, concerning the identification of this event as an aurora. Stephenson (2015) did not discuss why it was not classified as aurora in Yau, Stephenson \& Willis (1995), nor did he consider the halo hypothesis, or the fact that the white phenomenon appeared in the eastern to southern direction, not in the north.

Regarding the question of whether this event was observed on the jiazi or bingzi day, Stephenson (2015) writes that Keimatsu mistakenly cites the day ... jiazi rather than bingzi, but Keimatsu in fact gave both text variants in Chinese script (also shown here at the bottom our Fig. 1); Stephenson (2015) did not discuss the inconsistent lunar phase on one of the two dates, nor did he specify any other reason as to why the jiazi day was wrong.

\section{Likely true Chinese aurorae observations from AD 757 to the 770s}

Here, we briefly cite the Chinese reports of likely true aurorae in the AD 760s and 770s, in order to show how reports of true aurorae read. Our translations are provided below, the Chinese texts in Fig. 2.

These reports mention night-time, northern direction, as well as red colour, all typical for very likely true aurorae. Most reports are dated within a few days around the new moon, when it is very dark at night. Three examples of very likely true aurorae occurred in AD 762.

\subsection{AD 762 May 1: on the night ... red light ... NW}

AD 762 May 1, Shaanxi, China (new moon Apr 28/29):

The Daizong Emperor took the throne. In the same month, on the night of renzi [in the first year of the Baoying reign period, AD 762 May 1], a red light appeared in the northwest. Its flames shined bright and stretched across the sky, penetrating $\mathrm{Zi}$ wei [the circumpolar region]. It gradually flowed eastward, slowly filling the north. It shined round for several tens of li, and after a long time, it dispersed.

From Jiu Tang shu 36.1325, also as aurora in Keimatsu (1973) (certain aurora), Yau et al. (1995), and Xu et al. (2000).

Yau et al. (1995) gave the date as the second year of the Baoying reign period (AD 762). The discrepancy in our translations arises from an anomalous situation during the transition from the reign of Emperor Suzong (r. AD 756761) to the reign of Emperor Daizong (r. AD 762-779). The previous reign period, Shangyuan, had been ended but not been replaced in the ninth month of its second year, AD 761 Oct 3-Nov 1. The Baoying period did not in fact begin until the fourth month of the next year, AD 762 Apr 29-May 27. Thus, there is a gap between the two reign periods. Yau et al. (1995) seem to treat the end of the Shangyuan reign period as if it were the beginning of the Baoying, and thus treat AD
762 as its second year. (This also holds for the next events in AD 762, Sect. 3.2 and 3.3.)

As far as the $l i$ is concerned, the actual distance varied. It was equivalent to 300 paces or 1800 Chinese feet in Tang times, roughly one-third of a mile. Hence, the total estimated length was several times $5-6 \mathrm{~km}$ (one Chinese foot being $30.3 \mathrm{~cm}$ ). (To estimate the linear length, one would of course need to know the distance, which was probably very roughly estimated.) The large size given suggests an easily visible, impressive phenomenon. Yau et al. (1995) translated the word he as blazing flames; it may indicate the color red, an appearance of anger, something that is eye-catching, or act as a verb meaning shine brightly; we prefer its flames shined bright.

There is another report with almost the same wording hence, probably about the same event (but leaving out the exact date and that it occurred at night) at a slightly later time in the same year, AD 762 Jul/Aug (between Jul 26 and Aug 23), China:

In the seventh month of the 1st year of the Baoying reign period of the Daizong Emperor [AD 762 Jul 26 to Aug 23], there was a red light in the northwest that stretched across the sky, penetrating Ziwei [the circumpolar region]. It gradually flowed eastward, slowly filling the north. It shined round for several tens of li.

From Wenxian tongkao (AD 1254-1323), also listed in Dai $\&$ Chen (1980) and the Silverman online catalog (for AD 762 Aug for Xi'an, China).

The language of the passage largely matches that of the AD 762 May 1 event as recorded in Jiu Tang shu 36.1325. The wording also overlaps, partially, with the AD 762 Sep 16 event. The Wenxian tongkao passage (also cited in Dai \& Chen 1980) uses language almost identical to that of the Jiu Tang shu, but places the event in the seventh month of the same year (AD 762 Jul 26 to Aug 23). However, this date is perhaps due to copyist error of two nearly homophonous characters. Whereas the Jiu Tang shu has the phrase qi yue meaning the month of his accession. the Wenxian tongkao has qi yue meaning the seventh month. The two qi characters were pronounced in different tones, however, so our hypothesis remains tentative. In any case, there were credible aurorae in the year AD 762.

\subsection{AD 762 May 20: On the night ... red light}

AD 762 May 20, Jiangling county, Hubei, China (new moon May 27/28):

On the night of xinwei [in the fourth month of the 1st year of the Baoying reign period, AD 762 May 20], in Jiangling a red light appeared which penetrated Beidou [the Big Dipper in UMa, i.e. north].

From Jiu Tang shu 36.1325, also listed as an aurora in Keimatsu (1973) (very probable), Yau et al. (1995), and Xu et al. (2000); Yau et al. (1995) again had the 2nd year of the Baoying reign period, AD 762, see comment in Sect. 3.2. 


\section{Chinese Texts Section 3}

\subsection{AD 762 May 1:}

代宗即位。其月壬子夜, 西北方有赤光見, 炎赫瓦天, 貫紫微, 漸流于東, 瀰漫北方, 照 耀數 十里, 久之乃散。

(Jiu Tang shu 36.1325 / Liu 1975)

Additional report:

代宗寶應元年七月，西北方有赤光瓦天，貫紫微，漸流于東，濔漫北方，照耀數十里。 (Dai and Chen 1980: Wenxian tongkao 194.2329a / Ma 1986)

3.2 AD 762 May 20:

辛未夜, 江陵見赤光貫北斗。

(Jiu Tang shu 36.1325 / Liu 1975)

\subsection{AD 762 Sep 16:}

庚午夜，西北有赤光瓦天，貫紫微，漸移東北，彌漫半天。 (Jiu Tang shu 11.270 / Liu 1975)

Fig. 2 Here, we show the Chinese texts related to likely true aurorae. Translation and discussion are given in the Sect. 3. 


\subsection{AD 762 Sep 16: On the night ... NW ... red light}

AD 762 Sep 16, Shaanxi, China (new moon on Sep 22):

On the night of gengwu [in the eight month or the 1st year of the Baoying reign period, AD 762 Sep 16], in the northwest there was a red light that stretched across the sky, penetrating Ziwei [circumpolar]. It gradually moved northeast, until it filled half the sky.

From Jiu Tang shu 11.270, also listed as a certain aurora in Keimatsu (1973), Yau et al. (1995), and Xu et al. (2000). In the Yau et al. (1995) and Xu et al. (2000) translation, only the NE direction is mentioned, not the NW, but both NW and NE directions are clearly in the original Chinese text; Yau et al. (1995) again had the 2nd year of the Baoying reign period, AD 762, see comment in Sect. 3.2.

This text from Xi'an, the modern capital of Shaanxi, written by official court astronomers, shows how systematic the night reports are, listing the date, the fact that it occurred at night, its direction in the sky, colour, area in the sky, motion, and extent - similar to the Jiu Tang shu report in Sect. 3.1. The text partly overlaps with the Wenxian tongkao report given in Sect. 3.1, and may be a duplication.

\section{Questionable aurora reports AD 757-779}

Now, we also list those celestial observations from East Asia from $\mathrm{AD} 757$ to the end of the 770s, where the interpretation is uncertain, so that they could either be aurora or something else. Again, we give our translations, and the Chinese texts can be found in Fig. 3.

\subsection{AD 757 Feb 20: in the night ... four white rainbows}

AD 757 Feb 20, Nanyang, China (new moon Feb 22/23):

On the bingzi day [13] of the first month of the second year of the Zhide reign period [AD $757 \mathrm{Feb}$ 20], in the night, at Nanyang, there were four white rainbows [hong]. These extended upwards for more than one hundred zhang.

From Xin Tang shu 36.950, also listed as an aurora in Keimatsu (1973) (probable to doubtful), Yau et al. (1995), and $\mathrm{Xu}$ et al. (2000).

There are several different words conventionally translated as rainbow in classical Chinese. Daidong appears in the Odes classic (Shijing, while both $n i$ and hong appear in astronomic and omenological texts, where they are largely used synonymously. A distinction is sometimes drawn in the genders of the $n i$ and the hong; the term $n i$ often occurs in the phrase $c i n i$, a female rainbow. These words should perhaps be construed somewhat more broadly than the English rainbow, as they can occur at night, and can be white rather than multi-coloured. The entry in Xin Tang shu 36.950 for the AD 757 Feb 20 event uses the single most common of these, hong. Unlike the English word rainbow, hong is composed of a single element, not two independently meaningful morphemes, rain and bow. There is no commonly used single word meaning night rainbow in classical Chinese. One might suspect that the word for bow would be used for halos, but the word for bow, as in a bow and arrow, is gong. It is quite distinct from hong, both in sound and graphic form, and does not normally enter into astronomical discourse. The most common word for halo is perhaps huan, which in common discourse simply means ring.

While the term hong usually refers to a circular or semicircular glow, the event cannot be a lunar halo display nor a night rainbow, because it was near the new moon, and it could not have been solar halo display, because it was at night. A zhang is ten Chinese feet, i.e. $303 \mathrm{~cm}$ in Tang times for general measurements, or ten degrees in astronomy (Wilkinson 2000); since a celestial phenomenon cannot have the size of 1000 degrees (one hundred zhang) or more, the word zhang here stands for the linear length (ten Chinese feet). The wording more than 100 zhang refers to the height - being more than $300 \mathrm{~m}$. The report is not from the capital and is listed in a treatise on general omenology rather than astronomy. The text as it stands does not allow us to identify the precise nature of the phenomenon and caution is warranted in its interpretation.

\subsection{AD 760 Jul/Aug: northwest ... three green qi at dusk}

AD 760, between 17 July and 15 August, China:

In the sixth month of the third year of the Qianyuan reign period, in the northwest there were three green qi at dusk.

From Xin Tang shu 34.882, also as aurora in Dai \& Chen (1980), Yau et al. (1995), and Xu et al. (2000).

Dusk is more or less equivalent to the Chinese word it renders, hun. It implies that it is already getting dark and generally indicates the time between sunset and nightfall. If the hun period means those $36 \mathrm{~min}$ mentioned in the introduction between sunset and the start of the first night-watch (Stevenson 1997), then the event would have occurred (at least mostly) during civil twilight, when it is still too bright for an aurora.

Qi can refer to clouds or aurorae. This record occurs in a treatise on omenology. The colour qing could refer to black, blue, or green colour. Given that the qi occurred in the northwest and had colour, it is possible that this was a blue or green aurora; it could have been dark enough for an aurora; it could also be some kind of a halo effect at or shortly after sunset (NW).

\subsection{AD 767 Oct 8: On the night ... white mist ... NW}

AD 767 Oct 8, Shaanxi, China (full moon Oct 12):

On the night of wuwu [AD 767 Oct 8], white mist rose up to Wei [in Scorpio] in the northwest, spreading across the sky. 


\section{Chinese Texts Section 4}

4.1 AD 757 Feb 20:

至德二載正月丙子, 南陽夜有白虹四, 上互百餘丈。

(Xin Tang shu 36.950 / Ouyang 1975)

4.2 AD $760 \mathrm{Jul} /$ Aug:

乾元三年六月, 昏, 西北有青氣三。

(Xin Tang shu 34.882 / Ouyang 1975)

4.3 AD 767 Oct 8:

戊午夜, 白霧起尾西北, 瀰漫瓦天。

(Jiu Tang shu 36.1326 / Liu 1975)

4.4 AD 770 Jun 20:

甲申, 西北白氣竟天。

(Jiu Tang shu 11.297 / Liu 1975)

4.5 AD 770 Jul 20:

甲寅, 白氣出西北方, 竟天。

(Jiu Tang shu 35.1327 / Liu 1975)

Fig. 3 Here, we show the Chinese texts related to questionable cases, which may or may not be aurorae. Translation and discussion are given in the Sect. 4. 
Keimatsu (1973) classified the event as a doubtful to probable aurora; the event is also listed as aurora in Yau et al. (1995) and - probably - also in Usoskin et al. (2013), but not in Xu et al. (2000).

The word for mist usually means fog $(w u)$, so that the classification as an aurora is uncertain. The phenomenon was seen projected onto a stellar constellation at night. However, as we can see in the chapters in Qutan Xida's (fl. 729) Kaiyuan zhan jing (Kaiyuan reign period [713-741] Classic of Prognostication) on omens of clouds and $q i$ encroaching on constellations, odd clouds or other meteorological phenomena can appear in particular constellations. The title of chapter 95 reads, for instance, Yunqi fan ershiba xiu zhan or Prognostications on Clouds and Qi Transgressing the 28 Lunar Lodges, the 28 lunar lodges being the constellations that make up the zodiacal band in Chinese astronomy.

An excavated manuscript from the Library Cave (Mogao ku) at Dunhuang (S. 3326), often referred to as the world's earliest extant star atlas, likewise suggests that clouds or misty formations comprised of various colours of $q i$ were read against constellations for the purposes of prognostication. The manuscript, produced between AD 649 and AD 684, contains a series of images of variously shaped cloud-like formations, a chart depicting some 257 asterisms containing 1,339 stars, and a robed figure brandishing a bow and arrow labeled "God of Lightning" (BonnetBidaud, Praderie, and Whitfield 2009). Scholarly interpretation of the manuscript has focused on its astronomical features and little attention has been paid to the portion of the manuscript containing the cloud-like formations. Both Bonnet-Bidaud, Praderie, and Whitfield (2009) and Sun \& Kistemaker (1997) present images of the portion of the manuscript containing the star chart, but neither present images of the cloud-like formations. However, when examined as a whole, the manuscript quite clearly shows the extent to which astronomical and meteorological phenomena were mutually integrated in medieval China.

\subsection{AD 770 Jun 20: $N W$... white qi ... across the sky}

AD 770 Jun 20, Shaanxi, China (moon's last quarter Jun 20/21):

On the jiashen [21] day [of the fifth month of the fifth year of the Dali reign period], in the northwestern direction, white qi permeated the sky.

From Jiu Tang shu 11.297, also in Yau et al. (1995) and Keimatsu (1973) (probable to doubtful), but not in Xu et al. (2000), because they omit all events, where it is not mentioned explicitly that they were observed at night-time. See the discussion in the next subsection.

\subsection{AD 770 Jul 20: $N W$... white qi ... across the sky}

AD 770, Jul 20, Shaanxi, China (moon's last quarter Jul 20):
On the jiayin [51] day [of the sixth month of the fifth year of the Dali reign period], white qi emerged in the northwest and permeated the sky.

From Jiu Tang shu 35.1327, also in Yau et al. (1995) and Keimatsu (1973) (probable to doubtful), but not in Xu et al. (2000).

It is likely that both reports refer to the very same event and that one of the two reports is a misdated copy of the other. The dates differ by exactly one month. The day in the sexagenary system is given as jia-shen (21) in the first report (i.e. AD 770 Jun 20) and jia-yin (51) in the 2 nd report (i.e. AD 770 Jul 20); both words consist of two parts, the first parts being identical. The graph for shen is quite similar to the lower portion of the graph for yin, and the two words could easily be mistaken for one another in a manuscript. However, the final redactions of the two passages seem to have taken this into account, appropriately placing the two entries in the 5th and 6th months. The former text is from the Basic Annals (Ben ji) of the reign of Emperor Daizong in the Jiu Tang shu (11.297), while the latter is from a treatise on general omenology, rather than celestial patterns, in the same larger historiographical project (35.1327). The discrepancy between the two passages might be explained in a number of ways: One passage might be an inaccurate paraphrase of the other; the two passages might represent varying reproductions of the same damaged manuscript; or the two passages might be based on two different manuscripts representing two different lines of transmission of the same original record. Neither is it beyond the realm of possibility that the two passages were in fact records of two independent events. Assuming they are records of the same event, it is impossible to determine which date is correct, if one of the two reports is a misdated copy of the other.

Since the reports for the last two events (AD 770 June and July) do not specify night-time, it is also not certain that they refer to aurorae. However, given the (slightly) different texts for June and July 770, we consider it possible that they refer to two distinct but similar events, possibly aurorae (northwest direction and qi ... across the sky). Given that about one month was between these two events, they could refer to auroral activity from a stable coronal hole.

\section{Chinese comet observations reported for the AD 770s}

Since a comet observation was also discussed in the context of the ${ }^{14} \mathrm{C}$ variation around $\mathrm{AD} 775$ (Liu et al. 2014), we also briefly review Chinese comet observations from the mid AD 770s.

\subsection{The comet of AD 773 January}

Liu et al. (2014) claimed that the Chinese had observed a comet that had collided with the Earth's atmosphere on AD $773 \mathrm{Jan} 17$, thus bringing extra ${ }^{14} \mathrm{C}$ into the atmosphere. 
Chinese Texts Section 5:

5.1 AD 773 Jan:

七年十二月丙寅, 有長星于參下, 其長瓦天。長星, 彗屬。參, 唐星也。 (Xin Tang shu 32.838 / Ouyang 1975)

5.2 AD 776 Jan 11 or AD 767 Jan 21/22

十二月, 月上白氣貫觜、參、井、鬼、柳、軒轅。彗出匏瓜, 犯宦者星。

(Gujin tushu jicheng, vol. 40, p. 33a, register 2 / Chen et al. 1934)

大曆元年十二月己亥, 有彗星于匏瓜, 長尺餘, 經二旬不見, 犯宦者星。 (Xin Tang shu 32.838 / Ouyang 1975)

大㦄元年十二月十七日, 彗見於湤瓜, 侵宦者星。長尺餘色赤二旬滅。

(Tang hui yao 43.4 / Wang 2007)

大㦄元年十二月, 彗星出匏瓜, 長尺餘, 犯宦者星。

(Premodern Jiu Tang shu 36.18 / Liu 2007)

Apparent misreadings

1) $j i$ 己 $\rightarrow y i$ 乙

2) yuan 元 $\rightarrow s h i$ 十

Fig. 4 Here, we show the Chinese texts related to comets. Translation and discussion are given in the Sect. 5. The apparent misreadings at the bottom are discussed in Sect. 5.2. 
However, as we have shown already (Chapman et al. 2014), this claim was not correct for several reasons:

1. The Chinese thought at that time that comets were inside the Earth's atmosphere, so that they could not interpret a comet observation as a collision with Earth.

2. The Chinese report presented in Liu et al. (2014) was culled from several different sources and inaccurately translated. The correct translation of the most extensive version of the record is:

On the bingyin day of the twelfth month of the seventh year (AD 773 Jan 17), there was a long star beneath Shen. Its length extended across the sky. Long stars belong to the class of comets. Shen is the constellation corresponding to the Tang (Xin Tang shu 32.838).

3. The comet was then observed by the Japanese on AD 773 Jan 20, so that it could not have collided with the Earth on Jan 17.

See Chapman et al. (2014) for details. This case was reexamined by Stephenson (2015) and fully confirmed.

\subsection{The presumable comet of AD 776}

Next, we discuss the presumable comet of AD 776, partly because it is reported in connection with the white $q i$ phenomenon, which may be the same as the one identified by Stephenson as an aurora.

It is highly probable that the comet Hasegawa (1980) cites as appearing on AD 776 Jan 11 (no. 437) is spurious, the result of a mistranscribed date. The details concerning the comet correspond very closely with those of an earlier comet appearing on AD 767 Jan 21 (no. 433).

Hasegawa (1980) cites the following passage in the 18th century encyclopedia Gujin tushu jicheng as the source for comet no. 437, Gujin tushu jicheng, vol. 40, p. 33a, register 2 (Chen et al. 1934):

In the 12th month [of the 10th year of the Dali reign period, $\mathrm{AD} 776 \mathrm{Jan}$ ], white qi above the moon penetrated Zui, Shen, Jing (Gem), Gui (Cnc), Liu, and Xuanyuan. A comet appeared in Hu Gua (Del). It fell into Huanzhe (Her).

In his notes on the comet no. 437, Hasegawa (1980) cites an unspecified Chinese record:

A Chinese record says: On a yihai day in the 12th month of the tenth year of the Dali reign-period [AD 776 Jan 11], a comet appeared at $\mathrm{Hu}$ Gua $(\alpha$, $\beta, \nu$ Del). It was several feet in length, and after 20 days it disappeared. It fell into Huanzhe (near $\alpha$ Her).

The Gujin tushu jicheng entry seems to conflate two separate events: An appearance of white $q i$ above the moon in AD 776 Jan (c.f. Sect. 2.7), and the appearance of a comet (Hasegawa comet no. 433), whose correct date is AD 767 Jan 21/22, as we will show below. Although the Gujin tushu jicheng entry does not specify a sexagenary date, the two events may have been conflated due to confusion between the yihai and jihai dates in the sexagenary calendar coupled with mistranscription of the year, as both occurred in 12th month of years in the Dali reign period. The yihai day (from Hasegawa's notes, see above) is the 12th day in the sexagenary calendar and immediately precedes the bingzi day (on which the appearance of white $q i$ in Sect. 2.7 was said to have occurred.) Jihai in contrast is the 36th day in the sexagenary calendar and is given as the date for the appearance of the AD 767 Jan 22 comet in Xin Tang shu 32.838 (Ouyang 1975). The preceding day, the 17th day of the lunar month corresponding to the 35th day in the sexagenary calendar (wuxu), AD 767 Jan 21, is given for the same event in Tang hui yao 43.4 (Wang 2007).

In his notes on comet no. 437, Hasegawa (1980) cites an unspecified Chinese record, which appears to include the portion of the Gujin tushu jicheng record pertaining to the comet, Hasegawa gives a date, which would correspond to AD 776 Jan 11, but is based on an erroneous yihai date. With the exception of the date, the unspecified record corresponds very closely with descriptions of the AD 767 Jan 21/22 comet.

Xin Tang shu 32.838 (Ouyang 1975):

On a jihai day [day 36 of the sexagenary cycle] in the 12th month of the first year of Dali reignperiod (AD 767 Jan 22), a comet appeared in $\mathrm{Hu}$ Gua. It was greater than one chi in length. After 20 days it was no longer seen. It fell into Huanzhe.

Tang hui yao 43.4 (Wang 2007) has a similar entry corresponding to Hasegawa (1980) for comet no. 433:

On the 17th day [of the lunar month, corresponding to the 35th day of the sexagenary cycle, wuxu] of the 12th month of the first year of the Dali reign period (AD 767 Jan 2117) a comet appeared in Hu Gua. It encroached on Huanzhe. It was greater than one chi in length, and its colour was red. After 20 days it vanished.

Jiu Tang shu 36.18 (Liu 1975):

In the 12th month of the first year of the Dali reign period a comet appeared in $\mathrm{Hu}$ Gua. It was greater than one chi in length. It fell into Huanzhe.

AD 767 Jan 22 was a jihai day. The initial appearance of the comet was in the Xin Tang shu recorded as having occurred on Jan 22. It would be very easy for $j i$ to be mistranscribed as the very similar graph $y i$, whether due to hastiness on the part of a scribe, or due to reproduction of a damaged manuscript, hence changing a jihai day to an yihai day. As noted in Yau et al. (1995), this particular error is extremely

7 According to eclipse.gsfc.nasa.gov/phase, new moon was AD 767 Jan 5 at $8: 13 \mathrm{~h}$ UT, i.e. around 15:30h local time in China, the 1st day of that month, so that the 17 th day of that lunar month was Jan 21 . The 17 th night of that month was Jan 21/22. The Chinese started the day-count in each month with what we call new moon, i.e. conjunction of moon and sun, as confirmed by the fact that all dates of solar eclipses from AD 700 to 1200 are dated to the first day of the month, see listing in Xu et al. (2000). 
common. In AD 776 Jan, there was an yihai day. It is also quite conceivable that yuan might be mistranscribed as shi, hence changing the date from the 1st year of the Dali reignperiod, AD 767, to the 10th year, AD 776. Given the remarkable similarities between the AD 767 comet and the presumable AD 776 comet, including the period for which they were visible, their lengths, and the particular constellations in which they appeared and toward which they traveled, we find it very likely that they were indeed the same comet and that the AD 776 date is the result of some error. The presumable AD 776 comet is also not listed in Ho Peng Yoke (1962).

What is reported by Chen et al. (1934) as white qi above the moon penetrated Zui, Shen, Jing (Gem), Gui (Cnc), Liu, and Xuanyuan, was neither identified nor considered as an aurora in any of the catalogues cited above. Indeed, it was not an aurora, because it appeared above the moon, similar to the event in Sect. 2.7. Instead, it could be the same event: While the phrases in the east, ten bands, Taurus and Auriga, and the dispersing were not mentioned in the Chen et al. (1934) source, the constellations mentioned to be above the moon are fully consistent with a dating around the full moon - given that the white qi phenomenon occurred in Jan 776 (Chen et al. 1934: in the 12th month). It could have happened on the bingzi day as mentioned in Sect. 2.7, i.e. it may have been the same event. 8

The Gujin tushu jisheng (without specifying a day) appears, therefore, to have conflated two separate events white qi and comet - on account of their (possibly) similar dates within the traditional calendar. The white $q i$ phenomenon most probably occurred on the night of AD 776 Jan 11/12 and/or 12/13 (see Sect. 2.7, halos sometimes do appear in subsequent nights), while the comet appeared on AD 767 Jan 21/22.

We also see that the Chinese reports - after correction of some mistakes in dates due to likely transcription erors are fully consistent in all details, so that the date correction is unambiguous and highly credible.

\subsection{The possible Korean comet in AD 776 June}

From the Samguk sagi, the Korean Lee Dynasty chronology during the reign of He Gong Chu (1968) cited a Hye Sung interpreted as nova or supernova candidate, which was observed from AD 776 Jun 1 to 30 in Tau-Aur.

\footnotetext{
8 While the comet was misdated to AD 776 Jan, we have to consider whether the white qi from the late Gujin tushu jicheng source (which gives year and month without day) may also be dated to AD 767 Jan. The event discussed in Sect. 2.7 gives the bingzi day of the 12th month [AD 776 Jan 12] (the moon rose in the east and above it there were more than 10 bands of white qi). There was no bingzi day (13th day of the sexagenary cycle) in the 12th month of that year in the Chinese lunar calendar, which started on AD 767 Jan 5 with the new moon. Hence, the event discussed in Sect. 2.7 could not have happened in AD 767.

We still have to consider, whether the yihai day from that unspecified source (reporting only the comet) may be related to the white qi on a bingzi day (see Sect. 2.7). The white qi could have happened on AD 776 Jan 11 and continued after midnight into the bingzi day AD 776 Jan 12 (see footnote 6).
}

Unfortunately, as Chu (1968) does not give a chapter or page in his citation of the Samguk sagi, we are unable to locate the event to which Chu (1968) refers in the historical chronicle. We might expect to see a record in the Basic Annals for the 12th year of the reign of King Hyegong (AD 776), but no such record is present. The Samguk sagi contains neither an omenological nor an astronomical treatise, so we can only assume that Chu (1968) refers to a passage contained in either a biographical chapter or another treatise in the text. The next closest comet in time around AD 776 is an AD 768 event reported in the Silla pon'gi section of Samguk sagi (9.95):

In the fourth year [of the reign of King Hyegong] in spring, a comet appeared in the NE.

(Silla pon'gi, Samguk sagi 9.95 / Kim 1977).

Since Hye Sung is an ancient Korean comet name, the object may be a comet observed for 30 days (it may have been referred to by a name for a comet, because it moved relative to the stars). The fact that Chu (1968) interpreted it as a nova or supernova may be due to the fact that neither a tail nor motion was mentioned in the original text. If it was a comet with a very short or faint (undetectable) tail, then this may indicate low solar activity at that time (June 776). The fact that it was not reported in any other source may also indicate that it was relatively faint.

\section{Conclusion: A cluster of East Asian aurora reports in the $770 \mathrm{~s}$ ?}

Based on new translations, philological considerations, historic backgrounds, precise date and time conversions, and astronomical calculations, we have shown that several historic Chinese reports were misinterpreted as aurorae, and that they were in fact something completely different, e.g. solar or lunar halos, fog, meteors, and so forth. In particular, misinterpretations and errors in dating call into question the conclusions of both Usoskin et al. (2013) and Zhou et al. (2014).

We conclude that there is neither evidence for a cluster of aurorae nor for any particularly strong aurorae in the AD 770 s in East Asian sources. However, the lack of aurora reports for the AD 770s is not due to the absence of observers or the loss of records, as there are Chinese reports about (other) celestial events from the decade. In particular, there are no aurora reports which would support the super-flare hypothesis for $\mathrm{AD} 774$.

There is a distinct cluster of very likely aurorae in AD 762; and there are good candidates in $\mathrm{AD} 757,760,767$, and 770 (one or two), which are, however, questionable for a variety of reasons outlined in section 4 .

Stephenson (2015) cites the events included in our Sect. 3 also as good examples of true aurorae. Of the eight events listed by us from AD 767 to 779, he lists six (all excluding those in our Sect. 2.4 and 2.6) plus one more (black 
qi). Stephenson (2015) does not consider the white qi observation in connection with the Chinese comet observation, the latter misdated for AD 776 (true AD 767). Stephenson (2015) does classify the event of AD 776 Jan 12 above the moon as an aurora, which we consider to be a halo effect. Stephenson (2015) and we agree that there is no evidence for strong East Asian aurorae around AD 774/5. As indicated by Stephenson (2014), the records of astronomical observations dating to the Dali reign period (AD 767-779) are particularly numerous. It is unlikely that any major observable astronomical phenomenon that occurred during that period is missing from its records.

As far as European observations of presumable aurorae in the mid AD 770s are concerned, as listed e.g. in Usoskin et al. (2013) or the Silverman catalog, for AD 773, 774, and 776 , Neuhäuser \& Neuhäuser $(2014,2015)$ have shown that all of them were in fact halo displays; two of those are also listed in Stephenson (2015), who considers at least one of them, the red cross of $\mathrm{AD} 776$, as a possible aurora.

The two Chinese comet reports in the mid AD 770s also do not relate to the ${ }^{14} \mathrm{C}$ increase: The comet of Jan 773 did not collide with the Earth's atmosphere (Chapman et al. 2014), and the comet reported for AD 776 was actually observed nine years earlier (Sect. 5.2).

Comet tail length and, hence, brightness, visibility, duration, and detection rates of comets depend on the solar wind.

For AD 773 Jan 17, there is a report about a Chinese comet: ... there was a long star beneath Shen (Orion). Its length extended across the sky .... See Sect. 5.1 and Chapman et al. (2014). This comet was also observed by the Japanese on (or since) AD 773 Jan 20; the fact that the observations are reported only for a few days (Jan 17 and 20) does not mean that it was observed solely in those nights, but could mean that it was observed first on those dates (Chapman et al. 2014). Stephenson (2015) also reexamines the evidence concerning the AD 773 comet, corroborating the conclusions of Chapman et al. (2014). Moreover, Hasegawa (1980) and Kronk (1999) list a Chinese comet for AD 776 Jan 11, but that is a misdated copy of the comet observed in AD 767 (Ho Peng Yoke (1962) does not list this extra comet), see Sect. 5.2.

Next, the nova or supernova candidate listed as Hye Sung in Chu (1968) for AD 776 Jun 1-30 in Tau-Aur (from the Korean Lee Dynasty chronology during the reign of $\mathrm{He}$ Gong) may be a comet, because it was named with an old Korean comet name (see Sect. 5.3). This event is not examined in Stephenson (2015).

According to Schove (1984), Ho Peng Yoke (1962), Hasegawa (1980), and Kronk (1999), there were no (other) comets detected worldwide until at least AD 812. This could be consistent with relatively strong solar wind (and related aurorae) until at least AD $773 \mathrm{Jan}$, but weak solar wind (few or no aurorae and short or no comet tails) since at least $\mathrm{AD}$ 776 June (for aurorae, see Neuhäuser \& Neuhäuser 2015). This consideration is speculative, because one would need to know the distance of the comet to convert from apparent to true (projected) length - but an apparent comet tail length might be considered a good first approximation.

Acknowledgements. We obtained the moon phases from Fred Espenak, NASA/GSFC (eclipse.gsfc.nasa.gov) and from Rita Gautschy on www.gautschy.ch/ rita/archast/mond/Babylonerste.txt.

We consulted the aurora catalog of Silverman on nssdcftp.gsfc.nasa.gov/miscellaneous/aurora. We thank V. Hambaryan for pointing us to the Korean comet observation of AD 776.

\section{References}

Ban G. et al., 32 CE-92 CE (comp.), Yan S. (581-645) comm. 1962, Han Shu (History of the Western Han), Zhonghua, Beijing

Bonnet-Bidaud, J.M., Praderie, F., Whitfield, S. 2009, The Dunhuang Chinese sky: a comprehensive study of the oldest known star atlas, International Dunhuang project, idp.bl.uk/education/astronomy_researchers/index.a4d\#totop

Chapman, J., Csikszentmihalyi, M., Neuhäuser, R., 2014, AN 335, 964

Chen M. (1651-ca. 1723) et al. comp., 1934, Gujin tushu jicheng (Collectanea of Ancient and Modern Charts and Books), Zhonghua, Shanghai

Chu, S., 1968, JKAS 1, 29

Cliver, E.W., Tylka, A.J., Dietrich, W.F., Ling, A.G., 2014, ApJ 781,32

Dai, N. \& Chen, M., 1980, Kejishi wenji 6, 87

Hambaryan, V.V. \& Neuhäuser, R., 2013, MNRAS 430, 32

Hasegawa, I., 1980, Vistas, 24, 73

Ho Peng Yoke, 1962, Vistas 5, 172

Jull, A.J.T., Panyushkina, I.P., Lange, T.E., et al., 2014, GeoRL 41, 3004

Keimatsu, M., 1970, A chronology of aurorae and sunspots in China, Korea, and Japan, Part I (centuries BC), Ann. Sci. Kanazawa Univ. Report 7, 1-6

Keimatsu, M., 1973, A chronology of aurorae and sunspots in China, Korea, and Japan, Part IV (6-8 century), Ann. Sci. Kanazawa Univ. Report 10, 1-32 (K73)

Keimatsu, M., 1974, A chronology of aurorae and sunspots in China, Korea, and Japan, Part V (AD 800-1000), Ann. Sci. Kanazawa Univ. Report 11, 1-36

Kim P. (1075-1151), Samguk sagi (History of the Three Dynasties), Vol. 2, Uryu Munhwasa, Seoul

Kronk, G.W., 1999, Cometography Vol. 1, Cambridge Univ. Press, Cambridge, UK

Link, F., 1962, Geofysikalni Sbornik 10, 297

Liu, X. (AD 887-946), 1975, Jiu Tang shu (Old History of the Tang Dynasty), Zhonghua, Beijing

Liu, X., 2007, Jiu Tang shu (Old History of the Tang Dynasty), In: Siku Quanshu (Complete Books of the Four Chambers), Wenyuange edition

Liu, Y., Zhang, Z., Peng, Z., et al., 2014, Nat SR 4E3728

Ma D. (ca. AD 1254 to ca. 1323) 1986, Wenxian tongkao, 2 Vols., Zhonghua, Beijing

Matsushita, S., 1956, J. Geophys. Res. 61, 297

Melott, A., 2014, pre-print, arXiv:1401.7276

Melott, A.L. \& Thomas, B.C., 2012, Nat 491, E1

Minnaert, M.G.J., 1993, Light and color in the outdoors, Springer New York 
Miyake, F., Nagaya, K., Masuda, K., Nakamura, T., 2012, Nat 486, 240

Neuhäuser, D.L. \& Neuhäuser, R., 2014, Halo-Code und HaloVergessenheit, in: Wolfschmidt, G. (Ed.) Proc. Der Himmel über Tübingen - Barocksternwarten - Landesvermessung Hochenergieastrophysik, Nuncius Hamburgensis, Vol. 28, pp 470-518 (english version in prep.)

Neuhäuser, R. \& Hambaryan, V.V., 2014, AN 335, 949

Neuhäuser, R. \& Neuhäuser, D.L., 2015, AN 336, 225

Qutan X. (fl. 729), Kaiyuan zhanjing (Kaiyuan reign period Classic of Prognostication), In: Siku Quanshu

Ouyang X. (AD 1007-1072) 1975, Xin Tang shu (New History of the Tang Dynasty), Zhonghua, Beijing

Schove, D.J., 1984, Chronology of eclipses and comets AD 11000, St. Edmundsburry Suffulk

Silverman, S., 1998, JASTP 60, $997 \quad$ (nssdcftp.gsfc.nasa.gov/miscellaneous/aurora)

Sima Q. (ca. 145 - ca. 86) 1959, Shiji (Historical Records), Zhonghua, Beijing

Stephenson, F.R., 1997, Historical eclipses and Earth's rotation, Cambridge Univ. Press

Stephenson, F.R., 2015, Adv. Sp. Res. 55, 1537

Su E (fl. AD 886), Duyang zazhi (Du Yang Miscellany), In: Siku Quanshu

Sun, X. \& Kistemaker, J., 1997, The Chinese sky during the Han: constellating stars and society, Brill, Leiden, New York, and Köln

Usoskin, I.G. \& Kovaltsov, G.A., 2012, ApJ 757, 92

Usoskin, I. \& Kovaltsov, G., 2014, pre-print, arXiv:1401.5945

Usoskin, I.G., Kromer, B., Ludlow, F., Beer, J., Friedrich, M., Kovaltsov, G.A., Solanki, S.K., Wacker, L., 2013, A\&A 552, L3

Wang P. (AD 922-982), 2007, Tang hui yao (Essential Records of the Tang Dynasty), In: Siku Quanshu

Wilkinson, E., 2000, Telling the time, in: Chinese history: A manual, 2nd ed., Cambridge, pp 198-219

Xu, Z., Pankenier, D.W., Jiang, Y., 2000, East Asian archaeoastronomy, Gordon and Breach, Amsterdam

Yau, K., Stephenson, F., Willis, D., 1995, A catalogue of auroral observations from China, Korea, and Japan (193 BC - AD 1770), Technical report, Rutherford Appleton Lab (YSW)

Zhou, D., Wang, C., Zhang, B., et al., 2014, Chin. Sci. Bull. (24 Apr 2014) DOI 10.1007/s11434-014-0345-Z 